\title{
About Capital in the Twenty-First Century
}

\author{
By Thomas Piketty*
}

In my view, Capital in the Twenty-First Century (Piketty 2014a) is primarily a book about the history of the distribution of income and wealth. Thanks to the cumulative efforts of several dozen scholars, we have been able to collect a relatively large historical database on the structure of national income and national wealth and the evolution of income and wealth distributions, covering three centuries and over 20 countries. My first objective in this book is to present this body of historical evidence, and to try to analyze the many economic, social, and political processes that can account for the various evolutions that we observe in the different countries since the Industrial Revolution. I stress from the beginning that we have too little historical data at our disposal to be able to draw definitive judgments. On the other hand, at least we have substantially more evidence than we used to. Imperfect as it is, I hope this work can contribute to put the study of distribution and of the long run back at the center of economic thinking. In this article, I present three key facts about inequality in the long run emerging from this research (see Figures 1-3 below; see also Piketty and Saez 2014) and seek to sharpen and refocus the discussion about those trends. In particular, I clarify the role played by $r>g$ in my analysis of wealth inequality. I also discuss some of the implications for optimal taxation, and the relation between capital-income ratios and capital shares.

\footnotetext{
* Paris School of Economics, 48 boulevard Jourdan, 75014 Paris, France (e-mail: piketty@psemail.eu). All statistical series and theoretical models used in this article and in my book are available in an online technical Appendix (http://piketty.pse.ens.fr/capital21c). Updated series are also available on the World Top Incomes Database (WTID) website (http//topincomes.parisschoolofeconomics.eu).

$\dagger$ Go to http://dx.doi.org/10.1257/aer.p1060 to visit the article page for additional materials and author disclosure statement(s).
}

\section{What $r>g$ Can and Cannot Explain}

In my analysis, the size of the gap between $r$ and $g$, where $r$ is the rate of return on capital and $g$ the economy's growth rate, is one of the important forces that can account for the historical magnitude and variations in wealth inequality. In particular, it can contribute to explain why wealth inequality was so extreme and persistent in pretty much every society up until World War I (see Piketty 2014a, ch. 10).

That said, the way in which I perceive the relationship between $r>g$ and inequality is often not well captured in the discussion that has surrounded my book. For example, I do not view $r>g$ as the only or even the primary tool for considering changes in income and wealth in the twentieth century, or for forecasting the path of inequality in the twenty-first century. Institutional changes and political shockswhich to a large extent can be viewed as endogenous to the inequality and development process itself-played a major role in the past, and it will probably be the same in the future.

In addition, I certainly do not believe that $r>g$ is a useful tool for the discussion of rising inequality of labor income: other mechanisms and policies are much more relevant here, e.g., supply and demand of skills and education. For instance, I point out in my book (Piketty 2014a, ch. 8-9) that the rise of top income shares in the United States over the 1980-2010 period is due for the most part to rising inequality of labor earnings, which can itself be explained by a mixture of two groups of factors: rising inequality in access to skills and to higher education over this time period in the United States, an evolution which might have been exacerbated by rising tuition fees and insufficient public investment; and exploding top managerial compensation, itself probably stimulated by changing incentives and norms, and by large cuts in top tax rates (see also Piketty 2014a, ch. 14; Piketty, Saez, and Stantcheva 2014). In any case, this rise in labor income inequality in recent decades has 


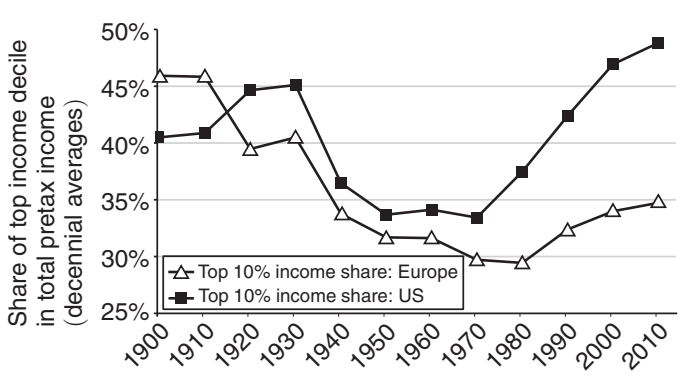

Figure 1. Income IneQuality: Europe AND the UNITED STATES, 1900-2010

Note: The share of total income accruing to top decile income holders was higher in Europe than in the United States around 1900-1910; it is a lot higher in the United States than in Europe around 2000-2010.

Source: See Piketty (2014b, fig. 9.8).

evidently little to do with $r-g$, and it is clearly a very important historical development. Indeed it explains why total income inequality is now substantially higher in the United States than in Europe, while the opposite was true until World War I (see Figure 1). At that time, high inequality was mostly due to extreme concentration of capital ownership and capital income. Wealth inequality is currently much less extreme than a century ago, in spite of the fact that the total capitalization of private wealth relative to national income has now recovered from the 1914-1945 shocks (see Figures 2 and 3). One central question for the future is to better understand the conditions under which the concentration of property might return to pre-1914 levels.

\section{II. $r>g$ and The Amplification of Wealth Inequality}

I now clarify the role played by $r>g$ in my analysis of the long-run level of wealth inequality. Specifically, a higher $r-g$ gap will tend to greatly amplify the steady-state inequality of a wealth distribution that arises out of a given mixture of shocks (including labor income shocks).

Let me first say very clearly that $r>g$ is certainly not a problem in itself. Indeed, the inequality $r>g$ holds true in the steady-state equilibrium of the most common economic models, including representative-agent models where each individual owns an equal share of the capital stock. For instance, in the standard

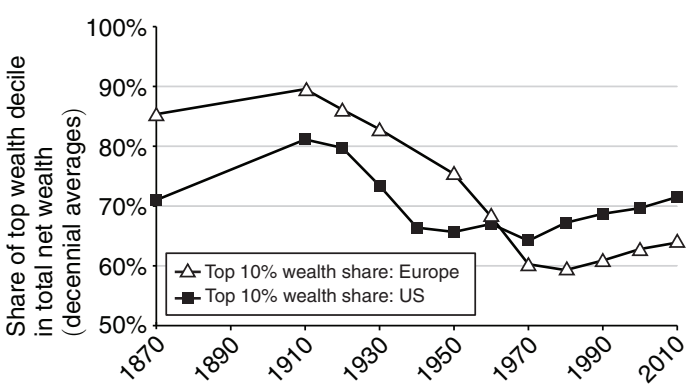

Figure 2. Wealth Inequality: Europe and the United STATES, 1870-2010

Notes: The share of total net wealth to top decile wealth holders has become higher in the United States than in Europe over the course of the twentieth century. But, it is still smaller than what it was in Europe before World War I.

Source: See Piketty (2014b, fig. 10.6).

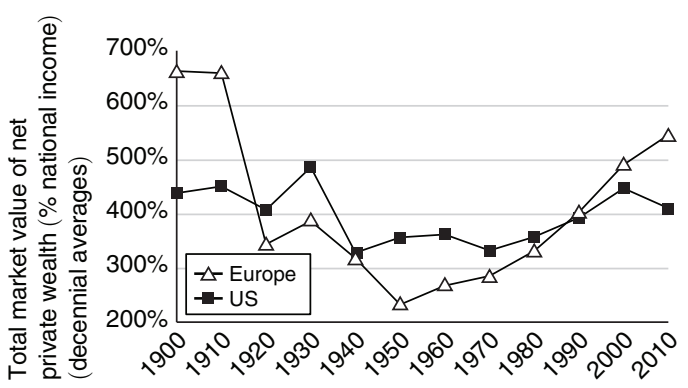

Figure 3. WeAlth-InCome Ratios: Europe AND the UNITED STATES, 1900-2010

Notes: Total net private wealth was worth about 6-7 years of national income in Europe prior to World War I, down to 2-3 years in 1950-1960, back up to 5-6 years in 20002010. In the United States, the U-shaped pattern was much less marked.

Source: See Piketty (2014b, fig. 5.1).

dynastic model where each individual behaves as an infinitely lived family, the steady-state rate of return is well known to be given by the modified "golden rule" $r=\theta+\gamma g$ (where $\theta$ is the rate of time preference and $\gamma$ is the curvature of the utility function). For example, if $\theta=3$ percent, $\gamma=2$, and $g=1$ percent, then $r=5$ percent. In this framework, the inequality $r>g$ always holds true, and does not entail any implication about wealth inequality. 
In a representative-agent framework, what $r>g$ means is simply that in steady-state each family only needs to reinvest a fraction $g / r$ of its capital income in order to ensure that its capital stock will grow at the same rate $g$ as the size of the economy, and the family can then consume a fraction $1-g / r$. For example, if $r=5$ percent and $g=1$ percent, then each family will reinvest 20 percent of its capital income and can consume 80 percent. This tells us nothing at all about inequality; this is simply saying that capital ownership allows the economy reach higher consumption levels-which is really the very least one can ask from capital ownership. ${ }^{1}$

So what is the relationship between $r-g$ and wealth inequality? To answer this question, one needs to introduce extra ingredients into the basic model so that inequality arises in the first place. ${ }^{2}$ In the real world, many shocks to the wealth trajectories of families can contribute to making the wealth distribution highly unequal (indeed, in every country and time period for which we have data, wealth distribution within each age group is substantially more unequal than income distribution, which is difficult to explain with standard life-cycle models of wealth accumulation). There are demographic shocks: some families have many children and have to split inheritances in many pieces, some have few; some parents die late, some die soon, and so on. There are also shocks to rates of return: some families make good investments, others go bankrupt. There are shocks to labor market outcomes: some earn high wages, others do not. There are differences in taste parameters that affect the level of saving: some families consume more than a fraction $1-g / r$ of their capital income, and might even consume the full

\footnotetext{
${ }^{1}$ The inequality $r<g$ would correspond to a situation which economists often refer to as "dynamic inefficiency": in effect, one would need to invest more than the return to capital in order to ensure that one's capital stock keeps rising as fast as the size of the economy. This corresponds to a situation of excessive capital accumulation.

${ }^{2}$ In the dynastic model with no shock, there is no force generating inequality out of equality (or equality out of inequality), so any initial level of wealth inequality (including full equality) can be self-sustaining, as long as the modified golden rule is satisfied. Note, however, that the magnitude of the gap $r-g$ has an impact on the steady-state inequality of consumption and welfare: if $r-g$ is small then high-wealth dynasties need to reinvest a large fraction of their capital income so that they do not consume much more than low wealth dynasties.
}

capital value; others might reinvest more than a fraction $g / r$ and have a strong taste for leaving bequests and perpetuating large fortunes.

A central property of this large class of models is that for a given structure of shocks, the long-run magnitude of wealth inequality will tend to be magnified if the gap $r-g$ is higher. In other words, wealth inequality will converge toward a finite level. The shocks will ensure that there is always some degree of downward and upward wealth mobility, so that wealth inequality remains bounded in the long run. But this finite inequality level will be a steeply rising function of the gap $r-g$. Intuitively, a higher gap between $r$ and $g$ works as an amplifier mechanism for wealth inequality, for a given variance of other shocks. To put it differently: a higher gap between $r$ and $g$ leads to a steady-state level of wealth inequality that is higher and more persistent over time (i.e., a higher gap $r-g$ leads both to higher inequality and lower mobility). Technically, one can indeed show that if shocks take a multiplicative form, then the inequality of wealth converges toward a distribution that has a Pareto shape for top wealth holders (which is approximately the form that we observe in real world distributions, and which corresponds to relatively fat upper tails and large concentration of wealth at the very top), and that the inverted Pareto coefficient (an indicator of top end inequality) is a steeply rising function of the gap $r-g$. The logic behind this well-known theoretical result (which was established by many authors using various structure of demographic and economic shocks) and this "inequality amplification" impact of $r-g$ is presented in Piketty (2014a, ch. 10). ${ }^{3}$

The important point is that in this class of models, relatively small changes in $r-g$ can generate large changes in steady-state wealth inequality. For example, simple simulations of the model with binomial taste shocks show that going from $r-g=2 \%$ to $r-g=3 \%$ is sufficient to move the inverted Pareto coefficient from $b=2.28$ to $b=3.25$. Taken literally, this corresponds to a shift from an economy with moderate wealth inequality - say, with a top 1 percent wealth share around $20-30$ percent, such

\footnotetext{
${ }^{3}$ For references to this literature on dynamic wealth accumulation models with random shocks, see Piketty (2014b). See also Piketty and Zucman (2015, sec. 5.4).
} 
as present-day Europe or the United States-to an economy with very high wealth inequality with a top 1 percent wealth share around 50-60 percent, such as pre-World War I Europe. ${ }^{4}$

Available micro-level evidence on wealth dynamics confirm that the high gap between $r$ and $g$ is one of the central reasons why wealth concentration was so high during the eighteenthnineteenth centuries and up until World War I (see Piketty 2014a, ch. 10; Piketty, Postel-Vinay, and Rosenthal 2006, 2014). During the twentieth century, it is a very unusual combination of events that transformed the relation between $r$ and $g$ (large capital shocks during the 1914-1945 period, including destruction, nationalization, inflation; high growth during the reconstruction period and demographic transition). In the future, several forces might push toward a higher $r-g$ gap (particularly the slowdown of population growth, and rising global competition to attract capital) and higher wealth inequality. But, ultimately, which forces prevail is relatively uncertain. In particular, this depends on the institutions and policies that will be adopted.

\section{On the Optimal Progressive Taxation of Income, Wealth, and Consumption}

I now move to the issue of optimal taxation. The theory of capital taxation that I present in Capital in the Twenty-First Century is largely based upon joint work with Emmanuel Saez (see, in particular, Piketty and Saez 2013). In this paper, we develop a model where inequality is fundamentally two-dimensional: individuals differ both in their labor earning potential and in their inherited wealth. Because of the underlying structure of demographic, productivity and taste shocks, these two dimensions are never perfectly correlated. As a consequence, the optimal tax policy is also two-dimensional: it involves a progressive tax on labor income and a progressive tax on inherited wealth. Specifically, we show that the long-run

\footnotetext{
${ }^{4}$ In the special case with binomial saving taste shocks with probability $p$, one can easily show that the inverted Pareto coefficient is given by $b=\log (1 / p) / \log (1 / \omega)$, with $\omega=s e^{(r-g) H}$ ( $s$ is the average saving taste, $r$ and $g$ are the annual rate of return and growth rate, and $H$ is generation length). See Piketty and Zucman (2015, sec. 5.4) for simple calibrations. Atkinson, Piketty, and Saez (2011, figs. 12-15) provide evidence on the long-run evolution of Pareto coefficients.
}

optimal tax rates on labor income and inheritance depend on the distributional parameters, the social welfare function, and the elasticities of labor earnings and capital bequests with respect to tax rates. The optimal tax rate on inheritance is always positive, except of course in the extreme case with an infinite elasticity of capital accumulation with respect to the net-of-tax rate of return (as posited implicitly in the benchmark dynastic model with infinite horizon and no shock used by Mankiw (2015) and others). For realistic empirical values, we find that the optimal inheritance tax rate might be as high as 50-60 percent, or even higher for top bequests, in line with historical experience.

Next, if we introduce capital market imperfections, then one needs to supplement inheritance taxes with annual taxation of wealth and capital income. Intuitively, in the presence of idiosyncratic shocks to future rates of return, it is impossible to know the lifetime capitalized value of an asset at the time of inheritance, and it is optimal to split the tax burden between these different tax instruments. Optimal tax formulas become relatively complicated and difficult to calibrate, however. In my book, I propose a simple rule of thumb to think about optimal wealth tax rates. Namely, one should adapt the tax rates to the observed speed at which the different wealth groups are rising over time. For instance, if top wealth holders are rising at 6-7 percent per year in real terms (as compared to 1-2 percent per year for average wealth), as suggested by Forbes-type wealth rankings (as well as by recent research by Saez and Zucman 2014), and if one aims to stabilize the level of wealth concentration, then one might need to apply top wealth tax rates as large as 5 percent per year, and possibly higher (see Piketty 2014a, ch. 15 and ch. 12, Tables 12.1-12.2). Needless to say, the implications would be very different if top wealth holders were rising at the same speed as average wealth. One of the main conclusions of my research is indeed that there is substantial uncertainty about how far income and wealth inequality might rise in the twenty-first century, and that we need more financial transparency and better information about income and wealth dynamics, so that we can adapt our policies and institutions to a changing environment. This might require better international fiscal coordination, which is difficult but by no means impossible (Zucman 2014). 
An alternative to progressive taxation of inheritance and wealth is the progressive consumption tax (see, e.g., Gates 2014; Auerbach and Hassett 2015; Mankiw 2015). This is a highly imperfect substitute, however. First, meritocratic values imply that one might want to tax inherited wealth more than self-made wealth, which is impossible to do with a consumption tax alone. Next, the very notion of consumption is not very well defined for top wealth holders: personal consumption in the form of food or clothes is bound to be a tiny fraction for large fortunes, who usually spend most of their resources in order to purchase influence, prestige and power. When the Koch brothers spend money on political campaigns, should this be counted as part of their consumption? When billionaires use their corporate jets, should this be included in consumption? A progressive tax on net wealth seems more desirable than a progressive consumption tax, first because net wealth is easier to define, measure, and monitor than consumption, and next because it is a better indicator of the ability of wealthy taxpayers to pay taxes and to contribute to the common good (see Piketty 2014a, ch.15).

Finally, note that in Capital in the TwentyFirst Century, I devote substantial attention to progressive taxation, but also to the rise of social transfers and the modern welfare state. As rightly argued by Weil (2015), social security and other transfers have played a large role to reduce inequality in the long run (see Piketty 2014a, ch.13).

\section{Capital-Income Ratios versus Capital Shares: Toward a Multi-Sector Approach}

One of the important findings from my research is that capital-income ratios $\beta=K / Y$ and capital shares $\alpha$ tend to move together in the long run, particularly in recent decades, where both have been rising. In the standard one-good model of capital accumulation with perfect competition, the only way to explain why $\beta$ and $\alpha$ move together is to assume that the capital-labor elasticity of substitution $\sigma$ is somewhat larger than one (which could be interpreted as the rise of robots and other capital-intensive technologies). ${ }^{5}$

\footnotetext{
${ }^{5}$ With $Y=F(K, L)=\left[a K^{(\sigma-1) / \sigma}+(1-a) L^{(\sigma-1) / \sigma}\right]^{\sigma /(\sigma-1)}$, the marginal productivity of capital is given by $r=F_{K}$
}

Let me make clear however this is not my favored interpretation of the evidence. Maybe robots and high capital-labor substitution will be important in the future. But at this stage, the important capital-intensive sectors are more traditional sectors like real estate and energy. I believe that the right model to think about rising capital-income ratios and capital shares in recent decades is a multi-sector model of capital accumulation, with substantial movements in relative prices, and with important variations in bargaining power over time (see Piketty 2014a, ch. 3-6). As rightly argued by Weil (2015), large upward or downward movements of real estate prices play an important role in the evolution of aggregate capital values during recent decades, as they did during the first half of the twentieth centuries. This can in turn be accounted for by a complex mixture of institutional and technological forces, including rent control policies and other rules regulating relations between owners and tenants, the transformation of economic geography, and the changing speed of technical progress in the transportation and construction industries relative to other sectors (see Piketty 2014a, ch. 3-6; Piketty and Zucman 2014). In practice, intersectoral elasticities of substitution combining supply and demand forces can often be much higher than within-sector elasticities (see, e.g., Karababounis and Neiman 2014 about the role played by the declining relative price of equipment).

More generally, one reason why my book is relatively long is because I try to offer a relatively detailed, multidimensional history of capital and its metamorphosis (from agricultural land to modern financial assets and immaterial capital). Capital ownership takes many different historical forms, and each of them involves different forms of property relations and social conflict, which must be analyzed as such (see, e.g., my analysis of slave capital in nineteenth century United States in Piketty 2014a, ch. 4; see also ch. 5 on the stakeholder German capitalism model, with large gaps between the social and market values of corporations). This multidimensional nature of capital creates substantial additional uncertain-

$=a(Y / K)^{1 / \sigma}=a \beta^{-1 / \sigma}$, and the capital share is given by $\alpha=r \beta=a \beta^{(\sigma-1) / \sigma}$. See Piketty and Zucman (2014, 2015). 
ties regarding the future evolution of inequality, as illustrated by the examples of housing and oil prices. In my view, this reinforces the need for increased democratic transparency about income and wealth dynamics.

\section{REFERENCES}

Atkinson, Anthony B., Thomas Piketty, and Emmanuel Saez. 2011. "Top Incomes in the Long Run of History." Journal of Economic Literature 49 (1): 3-71.

Auerbach, Alan J., and Kevin Hassett. 2015. "Capital Taxation in the Twenty-First Century." American Economic Review 105 (5). http://dx.doi.org/10.1257/aer.p20151058.

Gates, Bill. 2014. "Why Inequality Matters." Gates Notes (blog), October 13, 2014, http:// www.gatesnotes.com/Books/Why-InequalityMatters-Capital-in-21st-Century-Review.

Karabarbounis, Loukas, and Brent Neiman. 2014. "Capital Depreciation and Labor Shares around the World: Measurement and Implication." National Bureau of Economic Research Working Paper 20606.

Mankiw, Gregory. 2015. "Yes, $r>$ g. So What?" American Economic Review 105 (5). http://dx. doi.org/10.1257/aer.p20151059.

Piketty, Thomas. 2014a. Capital in the Twenty-First Century. Cambridge, MA: Harvard University Press.

Piketty, Thomas. 2014b. Capital in the Twenty-First Century. Cambridge, MA: Harvard University Press. Statistical series and technical appendix. http://piketty.pse.ens.fr/ capital21c.

Piketty, Thomas, Gilles Postel-Vinay, and Jean-Laurent Rosenthal. 2006. "Wealth Concentration in a Developing Economy: Paris and France, 1807-1994." American Economic
Review 96 (1): 236-56.

Piketty, Thomas, Gilles Postel-Vinay, and Jean-Laurent Rosenthal. 2014. "Inherited vs. Self-Made Wealth: Theory \& Evidence from a Rentier Society (Paris 1872-1927)." Explorations in Economic History 51: 21-40.

Piketty, Thomas, and Emmanuel Saez. 2013. "A Theory of Optimal Inheritance Taxation." Econometrica 81 (5): 1851-86.

Piketty, Thomas, and Emmanuel Saez. 2014. "Inequality in the long run." Science 344 (6186): 838-43.

Piketty, Thomas, Emmanuel Saez, and Stefanie Stantcheva. 2014. "Optimal Taxation of Top Labor Incomes: A Tale of Three Elasticities." American Economic Journal : Economic Policy 6 (1): 230-71.

Piketty, Thomas, and Gabriel Zucman. 2014. "Capital is Back: Wealth-Income Ratios in Rich Countries, 1700-2010." Quarterly Journal of Economics 129 (3): 1255-1310.

Piketty, Thomas, and Gabriel Zucman. 2015. "Wealth and Inheritance in the Long Run." In Handbook of Income Distribution. Vol. 2, edited by Anthony B. Atkinson and François Bourguignon, 1303-68. Amsterdam: Elsevier B. V.

Saez, Emmanuel, and Gabriel Zucman. 2014. "Wealth Inequality in the United States since 1913: Evidence from Capitalized Income Tax Data." National Bureau of Economic Research Working Paper 20625.

Weil, David N. 2015. "Capital and Wealth in the Twenty-First Century." American Economic Review 105 (5). http://dx.doi.org/10.1257/aer. p20151057.

Zucman, Gabriel. 2014. "Taxing Across Borders: Tracking Personal Wealth and Corporate Profits." Journal of Economic Perspectives 28 (4): $121-48$. 